\title{
Unilateral cleft lip: evaluation and comparison of treatment outcome with two surgical techniques based on qualitative (subject/guardian and professional) assessment
}

\author{
Adekunle Moses Adetayo ${ }^{1,2}$, Modupe Olushola Adetayo ${ }^{3}$, Wasiu Lanre Adeyemo ${ }^{4}$, Olutayo O. James ${ }^{4}$, \\ Michael O. Adeyemi ${ }^{4}$ \\ ${ }^{1}$ Department of Surgery, ${ }^{3}$ Department of Biochemistry, Benjamin Carson School of Medicine, Babcock University, \\ ${ }^{2}$ Dental Unit, Babcock University Teaching Hospital, Ilishan-Remo, \\ ${ }^{4}$ Oral and Maxillofacial Surgery, Department of Surgery, Lagos University Teaching Hospital, Idi-Araba, Nigeria
}

\begin{abstract}
J Korean Assoc Oral Maxillofac Surg 2019;45:141-151)
Objectives: The outcomes of the treatment of unilateral cleft lip can vary considerably due to variations in repair techniques. The aim of this study was to evaluate and compare treatment outcomes of surgical repair of unilateral cleft lip using either the Tennison-Randall or Millard technique based on (qualitative) parent/subject and professional assessments.

Materials and Methods: This was a prospective, randomized, controlled study conducted at Lagos University Teaching Hospital between January 2013 and July 2014. A total of 56 subjects with unilateral cleft lip presenting for primary surgery who satisfied the inclusion criteria were recruited for the study. Subjects were randomly allocated to surgical groups A or B through balloting. Group A underwent cleft repair with the Tennison-Randall technique, while group B underwent cleft repair with the Millard rotation advancement technique. Surgical outcome was assessed using qualitative evaluation by the guardian/subject and independent assessors based on a modified form of the criteria described by Christofides and colleagues.

Results: Of the 56 subjects enrolled in this study, 32 were male, with a male to female ratio of 1.3:1. Fifteen of the guardians/subjects in the Tennison-Randall group were most bothered about the lower part of the residual lip scar, while 12 guardians/subjects in the in the Millard group were most bothered about the upper part of the scar. More noses were judged to be flattened in the Millard group than in the Tennison-Randall group. Assessors observed a striking disparity in scar transgression of the philtral ridges between the two groups.

Conclusion: Essentially, there were no major difference in the overall results between Millard rotation-advancement and Tennison-Randall repairs. Both Millard and Tennison-Randall's techniques require significant improvements to improve the appearance of the scar on the upper part and lower part of the lip, respectively.
\end{abstract}

Key words: Unilateral cleft lip, Repair techniques, Evaluation of surgical outcome

[paper submitted 2018. 7. 20 / revised 2018. 9. 25 / accepted 2018. 10. 16]

\section{Introduction}

Presentations of patients with unilateral cleft lip/palate range from clefts involving only the vermilion to fullthickness clefts involving all tissue layers. These variations in

\section{Adekunle Moses Adetayo}

Department of Surgery, Benjamin Carson School of Medicine, Babcock University, PMB 4003, Ilishan-Remo, Ogun State 121103, Nigeria

TEL: +234-8038337845 FAX: +234-08087027716

E-mail: adetayoa@babcock.edu.ng

ORCID: https://orcid.org/0000-0002-7318-0810

(c) This is an open-access article distributed under the terms of the Creative Commons Attribution Non-Commercial License (http://creativecommons.org/ licenses/by-nc/4.0/), which permits unrestricted non-commercial use, distribution, and reproduction in any medium, provided the original work is properly cited. Copyright (C) 2019 The Korean Association of Oral and Maxillofacial Surgeons. All rights reserved. cleft lip presentation have led to the development of different repair techniques ${ }^{1}$ that have been employed over the years to repair unilateral cleft of the lip ${ }^{2}$. These techniques can be grouped into two broad groups: straight line techniques and those based on geometrically designed flaps ${ }^{3}$.

Straight line techniques have the potential for scar contracture with consequent shortening of the lip, as excess normal tissue along the cleft margins is sacrificed to achieve straightline closure and the shape of Cupid's bow is blunted ${ }^{3}$. These shortcomings have led to the use of geometrically designed flaps. Theoretical advantages of geometric techniques include applicability to a wide range of cleft sizes, the ability to symmetrically recreate Cupid's bow, achievement of adequate rotation and lip length, increased fullness of the philtral tu- 
bercle, and minimal wasted tissue $e^{4,5}$.

The two basic techniques that are in use for unilateral cleft lip repair, Tennison-Randall and Millard rotation-advancement techniques, are both variants of geometrically designed flap techniques. Both techniques recognize the importance of repositioning the lip muscle (orbicularis oris) in the correct anatomic orientation to achieve aesthetic as well as functional improvement ${ }^{6}$. These two techniques are the two most frequently employed techniques in Nigeria, where this study was conducted.

The ideal operation for repair of a unilateral cleft lip should result in a symmetrical upper lip with equal philtral column length on either side ${ }^{7}$. The scar should mirror the opposite side and should not transgress the philtral column ${ }^{7}$. There should also be no peaking at Cupid's bow at the cleft side or notching of the vermillion. In addition, Cupid's bow should be of adequate proportions ${ }^{7}$. Christofides and others opined that these criteria should be obtainable in a single operation without multiple minor revisional procedures ${ }^{8}$.

Because of variations in the sequence and timing of techniques, as well as the skills and experience of individual surgeons, the range of outcomes of treatment of cleft lip and palate can be considerable ${ }^{8}$; thus, evaluation of treatment outcomes is essential for identification and implementation of the highest possible standards of care ${ }^{7,9}$. In this regard, nasolabial appearance is, arguably, one of the most important measures of the success of treatment for unilateral cleft lip ${ }^{10}$, as it allows aesthetic correction of the deformity and progressive, balanced, development of the mid-face ${ }^{11}$. Methods to assess nasolabial appearance can be broadly divided into qualitative and quantitative methods. The latter methods aim to analyze the extent of abnormal morphology and the degree of disproportion objectively through facial measurements ${ }^{12}$. Qualitative methods are more subjective and involve analyses of facial esthetic and appearance impairment using scales, indices, scoring systems, and rankings. Subjective assessment of appearance and aesthetics is fraught with difficulty, but is most likely to reflect the patient's and general public's perception of facial impairment ${ }^{13}$.

There appear to be no published studies on the evaluation and comparison of these two basic treatment techniques in Nigeria. The purpose of this study was to evaluate and compare the treatment outcomes of surgical repair of unilateral cleft lip using either Tennison-Randall or Millard techniques based on (qualitative) parent/subject and professional assessment.

\section{Materials and Methods}

This was a prospective, randomized, controlled study of the treatment outcomes of surgical repair of unilateral cleft lip using either the Tennison-Randall or Millard techniques in Lagos University Teaching Hospital (Idi-Araba, Nigeria) between January 2013 and July 2014. A total of 56 subjects with unilateral cleft lip presenting for primary surgery who satisfied the 'rule of 10' were recruited for the study. Subjects with bilateral cleft lip and those who had undergone initial cleft surgery were excluded from the study.

The study was approved by the Health Research and Ethics Committee of Lagos University Teaching Hospital (approval No. 34512). Written informed consent was obtained from all subjects who were 16 years or older, and from the parents/guardians of subjects younger than 16 years before enrollment in the study. Subjects were randomly allocated to the two surgical technique repair groups through the use of balloting, namely a box containing sealed envelopes with 56 folded pieces of paper on which either " $A$ " or " $B$ " had been written. There were 28 pieces of paper with " $A$ " and 28 with "B". Subjects/guardians were asked to pick from the box after it had been thoroughly shaken. Group A were operated on using the Tennison-Randall technique, while group B were operated on using the Millard rotation advancement technique. Preoperatively, age, sex, weight, height, and type of cleft were recorded and cleft lip and palate were classified according to Kernahan and Stark ${ }^{14}$ as modified by the international confederation for Plastic and Reconstructive Surgery in $1971^{15}$.

\section{Preoperative evaluation}

Routine preoperative blood investigations including hemoglobin estimation, electrolyte, urea and creatinine levels, and electrocardiography were done for each subject. Echocardiography was also done when indicated. Subjects were referred to the pediatrician for clinical evaluation to rule out cardiovascular congenital anomalies, upper respiratory tract infection, ear infection, and other congenital anomalies that could be of clinical significance. Subjects were at least 3 months old, $4.5 \mathrm{~kg}$ (10 pounds), and had a minimum hemoglobin concentration of $10 \mathrm{~g} / \mathrm{dL}$.

\section{Operative procedure}

In subjects less than 12 years of age, surgical repair was done under general anesthesia with endotracheal intubation, 
while repairs for subjects above 12 years of age were done under local anesthesia with $2 \%$ xylocaine with adrenaline 1:80,000. Surgical repair was carried out by two consultant oral and maxillofacial surgeons experienced in cleft lip and palate surgery. One of the surgeons exclusively used Tennison-Randall's triangular technique ${ }^{16}$, while the other exclusively used Millard's rotation advancement technique ${ }^{17}$.

Postoperatively, sufratulle dressing was applied to the wound for the first 24 hours, and this was then followed by gentle daily cleansing with sterile normal saline applied with gauze swabs until the sutures on the skin were removed after 7 days. Closure of the surgical incision was done in layers using a $17.5 \mathrm{~mm}$ curved cutting needle. Vicryl (polyglactin) 4/0 was used for mucosa and muscles and nylon $4 / 0$ for skin in both groups of patients.

Subjects were reviewed weekly for two weeks post-surgery, and then once every month for 3 months to evaluate surgical outcome.

\section{Evaluation of surgical outcome}

Surgical outcome was assessed at 3 months using a qualitative method based on a modified form of the criteria described by Christofides et al. . (Appendices 1, 2) This evaluation was carried out by both the subjects/guardians (Appendix 1) and independent assessors.(Appendix 2) Scoring indices essentially assessed the appearance of the residual lip scar and nose.

Evaluation was carried out by two experienced surgeons (different from the operating surgeons) and the researcher. The three assessors met before commencement of the project to study the modalities of the scoring index. Initially, assessments were done independently and then together by the three assessors to resolve any differences in their findings. Final assessments were reached by consensus. Clinical evaluation was performed using modified criteria - scar transgression of the philtral ridges, symmetry of nostrils, and centrality of the columella, thickness of the lip scar, thickness of the scar at the nasal sill, peaking, notching - as described by Christofides et al. ${ }^{7}$ and as shown in the evaluation form. (Appendix 2)

For the second part of the qualitative assessment, the parents/guardians completed a questionnaire to assess satisfaction with treatment of their ward. The questionnaire was interpreted for the patients/guardians if they were not literate. The questionnaire consisted of evaluation of satisfaction with scar and nose appearance. Color, shape, and thickness of the scar were used to assess the patients/guardians opinions of the residual lip scar (Appendix 1), while the presence or absence of flattening of the nose at the cleft side, as well as deviation of the columella were used to assess the nose.(Appendix 1)

\section{Data analysis}

Data were analyzed using the SPSS for Windows (ver. 17.0; SPSS Inc., Chicago, IL, USA). Proportions and percentages were compared between groups using the chi-square test. Inter-rater reliability analysis using Cohen's kappa statistic was also performed to determine coherence among raters (inter-rater reliability was $0.85,95 \%$ confidence interval). A significance level of $P \leq 0.05$ was used.

\section{Results}

\section{Sex distribution of the subject population}

A total of 56 subjects requiring repair of unilateral cleft lip were enrolled in this study and analyzed. Twenty-eight subjects each were assigned to the Millard group and TennisonRandall (TR) group. Of the 56 subjects, 32 subjects (57.1\%) were males and the male:female ratio was $1.3: 1$. There were 15 males (53.6\%) and 13 females (46.4\%) (ratio of 1.2:1) in the Millard group and 17 males $(60.7 \%)$ and 11 females (39.3\%) (ratio of 1.6:1) in the TR group. There was no significant difference in sex ratio between the Millard and TR groups $(P=0.589)$.

\section{Age distribution of subjects}

The age of subjects at the time of lip repair ranged from 3 months to 51 years. Highest number of lip repairs was done within 3-6 months in both groups; Millard group, 21 subjects (75.0\%) and TR group, 17 subjects (60.7\%).(Table 1) There was no significant difference in age distribution between the

Table 1. Age distribution of the subjects

\begin{tabular}{lccc}
\hline Age group & $\begin{array}{c}\text { Millard group } \\
(\mathrm{n}=28)\end{array}$ & $\begin{array}{c}\text { Tennison-Randall } \\
\text { group }(\mathrm{n}=28)\end{array}$ & $\begin{array}{c}\text { Total } \\
(\mathrm{n}=56)\end{array}$ \\
\hline $3-6 \mathrm{mo}$ & $21(75.0)$ & $17(60.7)$ & $38(67.9)$ \\
$6-12 \mathrm{mo}$ & $3(10.7)$ & $8(28.6)$ & $11(19.6)$ \\
$1-6 \mathrm{yr}$ & $1(3.6)$ & $1(3.6)$ & $2(3.6)$ \\
$>6 \mathrm{yr}$ & $3(10.7)$ & $2(7.1)$ & $5(8.9)$ \\
\hline
\end{tabular}

Values are presented as number $(\%)$.

Adekunle Moses Adetayo et al: Unilateral cleft lip: evaluation and comparison of treatment outcome with two surgical techniques based on qualitative (subject/guardian and professional) assessment. J Korean Assoc Oral Maxillofac Surg 2019 
two groups $(P=0.408)$.

\section{Pattern of cleft lip and palate distribution}

Unilateral cleft lip, alveolus and palate was the commonest type of cleft deformity in the study ( $n=23,41.1 \%)$. There were more cleft deformities on the left side $(n=35,62.5 \%)$ than on the right side $(n=21,37.5 \%)$, corresponding to a ratio

Table 2. Comparison of different classes of clefts between the Millard and Tennison-Randall (TR) groups

\begin{tabular}{lrcccc}
\hline \multirow{2}{*}{ Group } & \multicolumn{4}{c}{ Classification of clefts } & \multirow{2}{*}{$P$-value } \\
\cline { 2 - 5 } & CL & CLA & CLAP & Total & \\
\hline Millard & 8 & 8 & 12 & 28 & \\
TR & 11 & 6 & 11 & 28 & 0.67 \\
Total & 19 & 14 & 23 & 56 & \\
\hline
\end{tabular}

(CL: cleft lip only, CLA: cleft lip and alveolus, CLAP: cleft lip, alveolus and palate)

Adekunle Moses Adetayo et al: Unilateral cleft lip: evaluation and comparison of treatment outcome with two surgical techniques based on qualitative (subject/guardian and professional) assessment. J Korean Assoc Oral Maxillofac Surg 2019

Table 3. Subject evaluation of surgical scars in the Millard and Tennison-Randall (TR) groups

\begin{tabular}{lccc}
\hline \multicolumn{1}{c}{ Surgical outcome } & $\begin{array}{c}\text { Millard group } \\
(\mathrm{n}=28)\end{array}$ & $\begin{array}{c}\text { TR group } \\
(\mathrm{n}=28)\end{array}$ & $P$-value \\
\hline Color of the scar & $26(92.9)$ & $26(92.9)$ & 0.513 \\
$\quad$ Very happy & $2(7.1)$ & $1(3.6)$ & \\
Happy & $0(0.0)$ & $1(3.6)$ & \\
Okay & $0(0.0)$ & $0(0.0)$ & 0.747 \\
Unhappy & & & \\
Texture of the scar & $22(78.6)$ & $21(75.0)$ & \\
Very happy & $3(10.7)$ & $2(7.1)$ & \\
Happy & $2(7.1)$ & $2(7.1)$ & \\
Okay & $1(3.6)$ & $3(10.7)$ & \\
Unhappy & & & 0.420 \\
Thickness of the scar & $21(75.0)$ & $22(78.6)$ & \\
Very happy & $4(14.3)$ & $1(3.6)$ & \\
Happy & $2(7.1)$ & $2(7.1)$ & \\
Okay & $1(3.6)$ & $3(10.7)$ & \\
Unhappy & & & 0.325 \\
Shape of the scar & $20(71.4)$ & $21(75.0)$ & \\
Very happy & $3(10.7)$ & $0(0.0)$ & \\
Happy & $4(14.3)$ & $5(17.9)$ & \\
Okay & $1(3.6)$ & $2(7.1)$ & \\
$\quad$ Unhappy & & & 0.637 \\
Width of the scar & $21(75.0)$ & $21(75.0)$ & \\
Very happy & $3(10.7)$ & $2(7.1)$ & \\
Happy & $3(10.7)$ & $5(17.9)$ & \\
Okay & $1(3.6)$ & $0(0.0)$ & \\
Unhappy & $3(10.7)$ & $9(32.1)$ & \\
Part of the scar that was the most bothersome & & \\
Upper part close to the nose & $12(42.9)$ & $4(14.3)$ & $0.028^{*}$ \\
Middle part & $13(46.4)$ & $15(53.6)$ & \\
Lower part close to the lip & & & \\
\hline
\end{tabular}

$* P \leq 0.05$.

Values are presented as number (\%).

Adekunle Moses Adetayo et al: Unilateral cleft lip: evaluation and comparison of treatment outcome with two surgical techniques based on qualitative (subject/guardian and professional) assessment. J Korean Assoc Oral Maxillofac Surg 2019 of 1.8:1. More males than females presented with cleft lips (32 [57.1\%] vs 24 [42.9\%]), corresponding to a male:female ratio of $1.33: 1$.

In the Millard group, unilateral cleft lip, alveolus and palate was the commonest type $(n=12,42.9 \%)$. A higher number of cleft lips were seen on the left side than on the right side (19 [67.9\%] vs 9 [32.1\%]).

In the TR group, 11 patients (39.3\%) each had cleft lip only versus cleft lip, alveolus and palate, while cleft lip and alveolus was seen in six subjects (21.4\%). More cleft lips $(n=16$, $57.1 \%)$ presented on the left side than on the right side $(n=12$, $42.9 \%$ ). There was no difference in the distribution of cleft lip patterns between the two groups.(Table 2).

\section{Subject evaluation of surgical outcomes}

In the evaluation of the color, texture, thickness, shape, and width of the scar, the vast majority of subjects/guardians $(92.9 \% ; 52$ of 56$)$ were very happy with the repair regardless of whether Millard or TR repair was used. There was no significant difference in subject/guardian satisfaction between the two groups $(P>0.05)$. (Table 3$)$

While six of the 28 subjects (21.4\%) who had surgical repair in the Millard group were not happy with the Cupid's bow, only two of the 28 subjects (7.1\%) in the TR group were unhappy with the Cupid's bow. This difference, however, was not statistically significant $(P=0.428)$. (Table 4$)$

While 15 of the 28 subjects (53.6\%) in the TR group were more bothered about the surgical outcome of the lower part of the scar close to the lip, 12 of the subjects $(42.9 \%)$ in the Millard group were more bothered about the upper part of the scar close to the nose. This difference was statistically significant $(P=0.028)$. (Table 3$)$

Twenty-five of the 28 subjects $(89.3 \%)$ in the Millard group judged the nostrils to be flattened, while 19 out of the 28 subjects $(67.9 \%)$ in the TR group judged the nostrils to

Table 4. Subject evaluation of Cupid's bow in Millard and Tennison-Randall (TR) groups

\begin{tabular}{lccc}
\hline Surgical outcome & $\begin{array}{c}\text { Millard group } \\
(\mathrm{n}=28)\end{array}$ & $\begin{array}{c}\text { TR group } \\
(\mathrm{n}=28)\end{array}$ & $P$-value \\
\hline Cupid's bow & & & 0.428 \\
Very happy & $9(32.1)$ & $11(39.3)$ & \\
Happy & $4(14.3)$ & $3(10.7)$ & \\
Okay & $9(32.1)$ & $12(42.9)$ & \\
Unhappy & $6(21.4)$ & $2(7.1)$ & \\
\hline
\end{tabular}

Values are presented as number $(\%)$.

Adekunle Moses Adetayo et al: Unilateral cleft lip: evaluation and comparison of treatment outcome with two surgical techniques based on qualitative (subject/guardian and professional) assessment. J Korean Assoc Oral Maxillofac Surg 2019 
be flattened. This difference between groups was statistically significant $(P=0.035)$. (Table 5)

There were more deviated columella in the Millard group than in the TR group (22 [78.6\%] vs 16 [57.1\%]), but this difference was not significant $(P=0.086)$. (Table 5)

\section{Assessor evaluation of surgical outcomes of the Millard and TR groups}

The assessors judged the scar on the lip to be level with the surroundings in 15 subjects (53.6\%) in the Millard group and 13 subjects $(46.4 \%)$ in the TR group. This difference was not statistically significant $(P=0.773)$.(Table 6) Although the number of the patients $(n=20,71.4 \%)$ judged to have a levelled scar at the nostril sill in the Millard group was greater than in the TR group $(n=12,42.9 \%)$, this difference was not

Table 5. Subject evaluation of the nostril in the Millard and Tennison-Randall (TR) groups

\begin{tabular}{lrrr}
\hline $\begin{array}{c}\text { Subjects response to } \\
\text { nasal repair }\end{array}$ & $\begin{array}{c}\text { Millard group } \\
(\mathrm{n}=28)\end{array}$ & $\begin{array}{c}\text { TR group } \\
(\mathrm{n}=28)\end{array}$ & $P$-value \\
\hline Nostril on the cleft side & & & $0.035^{*}$ \\
$\quad$ Flattened & $25(89.3)$ & $19(67.9)$ & \\
$\quad$ Not flattened & $3(10.7)$ & $9(32.1)$ & 0.086 \\
Columella deviation & & & \\
$\quad$ Deviated & $22(78.6)$ & $16(57.1)$ & \\
$\quad$ Not deviated & $6(21.4)$ & $12(42.9)$ & \\
\hline
\end{tabular}

$* P \leq 0.05$.

Values are presented as number $(\%)$.

Adekunle Moses Adetayo et al: Unilateral cleft lip: evaluation and comparison of treatment outcome with two surgical techniques based on qualitative (subject/guardian and professional) assessment. J Korean Assoc Oral Maxillofac Surg 2019

Table 6. Assessor evaluations of surgical outcomes of scars in Millard and Tennison-Randall (TR) groups

\begin{tabular}{|c|c|c|c|}
\hline Surgical outcome & $\begin{array}{l}\text { Millard } \\
\text { group } \\
(\mathrm{n}=28)\end{array}$ & $\begin{array}{c}\text { TR } \\
\text { group } \\
(\mathrm{n}=28)\end{array}$ & $P$-value \\
\hline Thickness of the lip scar & & & 0.773 \\
\hline Level with surroundings & 15 (53.6) & $13(46.4)$ & \\
\hline Depressed & $1(3.6)$ & $2(7.1)$ & \\
\hline Elevated & $12(42.9)$ & $13(46.4)$ & \\
\hline Thickness of scar at the nostril sill & & & 0.152 \\
\hline Level with surroundings & $20(71.4)$ & $12(42.9)$ & \\
\hline Depressed & $1(3.6)$ & $3(10.7)$ & \\
\hline Elevated & $7(25.0)$ & $13(46.4)$ & \\
\hline Scar transgression of the philtral ridge & & & $0.007 *$ \\
\hline Yes & $9(32.1)$ & $18(64.3)$ & \\
\hline No & $19(67.9)$ & $10(35.7)$ & \\
\hline Hypertrophic scar & & & 0.837 \\
\hline Yes & $7(25.0)$ & $6(21.4)$ & \\
\hline No & $21(75.0)$ & $22(78.6)$ & \\
\hline
\end{tabular}

$* P \leq 0.05$.

Values are presented as number $(\%)$.

Adekunle Moses Adetayo et al: Unilateral cleft lip: evaluation and comparison of treatment outcome with two surgical techniques based on qualitative (subject/guardian and professional) assessment. J Korean Assoc Oral Maxillofac Surg 2019 statistically significant $(P=0.152)$. (Table 6)

There was one more hypertrophic scar in the Millard group $(n=7,25.0 \%)$ than in the TR group $(n=6,21.4 \%)$, a nonsignificant difference.(Table 6)

Assessors observed a striking disparity in scar transgression of the philtral ridge in the two groups. This was present in $32.1 \%(n=9)$ of subjects in Millard group but $64.3 \%(n=18)$ of subjects in the TR group $(P=0.007)$.(Table 6)

In contrast, more peaking and notching were noticed in Millard repair than TR repair (13 and 10 vs 8 and 6, respectively), but this was not statistically significant $(P>0.05)$. (Table 7)

More nostrils were asymmetrical, more columellas were deviated, and more alae were flattened in the Millard group than in the TR group but without statistical significance $(P>0.05)$.(Table 8)

\section{Discussion}

Evaluation of treatment outcomes is essential for identification and implementation of the highest possible standards of

Table 7. Assessor evaluations of surgical outcomes of the lip in Millard and Tennison-Randall (TR) groups

\begin{tabular}{cccc}
\hline Surgical outcome & $\begin{array}{c}\text { Millard group } \\
(\mathrm{n}=28)\end{array}$ & $\begin{array}{c}\text { TR group } \\
(\mathrm{n}=28)\end{array}$ & $P$-value \\
\hline Peaking & $13(46.4)$ & $8(28.6)$ & 0.269 \\
Yes & $15(53.6)$ & $20(71.4)$ & \\
No & & & 0.375 \\
Notching & $10(35.7)$ & $6(21.4)$ & \\
Yes & $18(64.3)$ & $22(78.6)$ & \\
No & & \\
\hline
\end{tabular}

Values are presented as number (\%).

Adekunle Moses Adetayo et al: Unilateral cleft lip: evaluation and comparison of treatment outcome with two surgical techniques based on qualitative (subject/guardian and professional) assessment. JKorean Assoc Oral Maxillofac Surg 2019

Table 8. Assessor evaluations of surgical outcomes of the nose in Millard and Tennison-Randall (TR) groups

\begin{tabular}{lccc}
\hline Surgical outcome & $\begin{array}{c}\text { Millard group } \\
(\mathrm{n}=28)\end{array}$ & $\begin{array}{c}\text { TR group } \\
(\mathrm{n}=28)\end{array}$ & $P$-value \\
\hline Nostril symmetrical & & & 0.284 \\
$\quad$ Yes & $11(39.3)$ & $15(53.6)$ & \\
$\quad$ No & $17(60.7)$ & $13(46.4)$ & 0.131 \\
Centrality of columella & & & \\
$\quad$ Central & $18(64.3)$ & $23(82.1)$ & \\
$\quad \begin{array}{l}\text { Deviated } \\
\text { Ala on the cleft side }\end{array}$ & $10(35.7)$ & $5(17.9)$ & 0.285 \\
$\quad$ Normal & $12(42.9)$ & $16(57.1)$ & \\
$\quad$ Flattened & $16(57.1)$ & $12(42.9)$ & \\
\hline
\end{tabular}

Values are presented as number $(\%)$.

Adekunle Moses Adetayo et al: Unilateral cleft lip: evaluation and comparison of treatment outcome with two surgical techniques based on qualitative (subject/guardian and professional) assessment. J Korean Assoc Oral Maxillofac Surg 2019 
care $^{8,18}$. Few studies have compared the outcomes of different repair techniques of unilateral cleft lip ${ }^{5,19-26}$, and even fewer have compared the two most commonly used techniques ${ }^{27,28}$.

Nasolabial appearance is arguably one of the most important measures of the success of treatment for cleft lip repair ${ }^{10}$. Thus, we used nasolabial appearance to assess treatment outcomes in this study, consistent with previous studies ${ }^{5,26}$. Similarly, a residual scar in the nasolabial region as a result of cleft surgery has been used by various authors ${ }^{7,23,27,28}$ to assess the success of cleft lip repair. Most studies ${ }^{9,29-31}$ have concluded that increasing the number of assessors improves reliability and minimizes inter-examiner bias. Therefore, in our study, assessment was performed by three raters to reduce inter-rater bias.

Patient perception of the repair are a major consideration when evaluating outcomes of cleft repair ${ }^{7,31}$. Most respondents in our study were very happy with the appearance of the scar and therefore the repair in both Millard and TR groups $(92.9 \%)$. This means that surgical repair of unilateral cleft lip is important and can provide hope to distressed parents and patients. This is in agreement with prior studies ${ }^{7,23,32}$ where the majority of repairs with either technique were judged to be good by the parents/patients.(Fig. 1) A plausible explanation for this is that the parents/patients see the repair as a considerable improvement of the deformity. Other reasons for this are that parents/patients trust caregivers, and that they are concerned that complaints from them would be perceived as not appreciating the caregivers ${ }^{33}$. Respect for caregivers is another potential reason for the high satisfaction rates reported for parents/patients ${ }^{32}$.

Twenty-one percent of the respondents in the Millard group and $7 \%$ in the TR group were not satisfied with the Cupid's bow. Millard repair has been criticized by various authors ${ }^{19,23,34}$ as producing a wider than normal Cupid's bow. In contrast, TR repair produces a near normal Cupid's bow ${ }^{19,22,34}$. We did not find one technique superior to the other with respect to Cupid's bow. This may be related to the ability of the Millard's surgeon in this study to produce a normal-looking Cupid's bow.

Differences in the responders' perceptions of what part of the scar bothered them most revealed significant differences between the two techniques. Previous studies reported that both techniques produce a scar that bothers the patients/ guardians ${ }^{7,23,34,35}$. In this study, $43 \%$ of repairs in the Millard group produced a scar on the upper part of the lip that bothered the patient, while $53 \%$ of repairs in the TR group produced a scar on the lower part of the lip that bothered the patient.(Fig. 2) The scar on the upper part of the lip after Millard correction has been reported to be due to the rotation incision in the upper part of the lip, while the scar on the lower part of the lip after Tennison-Randall repair is generally agreed to be due to the triangular flap made in the lower part of the $\operatorname{lip}^{7,22}$.

There is consensus that Millard cleft lip repair produces better nasal symmetry than TR repair ${ }^{19,25}$. However, we found significantly more symmetrical noses in TR than in Millard repair subjects. This might be due to other factors not explored like width of the cleft and the skill of the surgeon ${ }^{19}$.
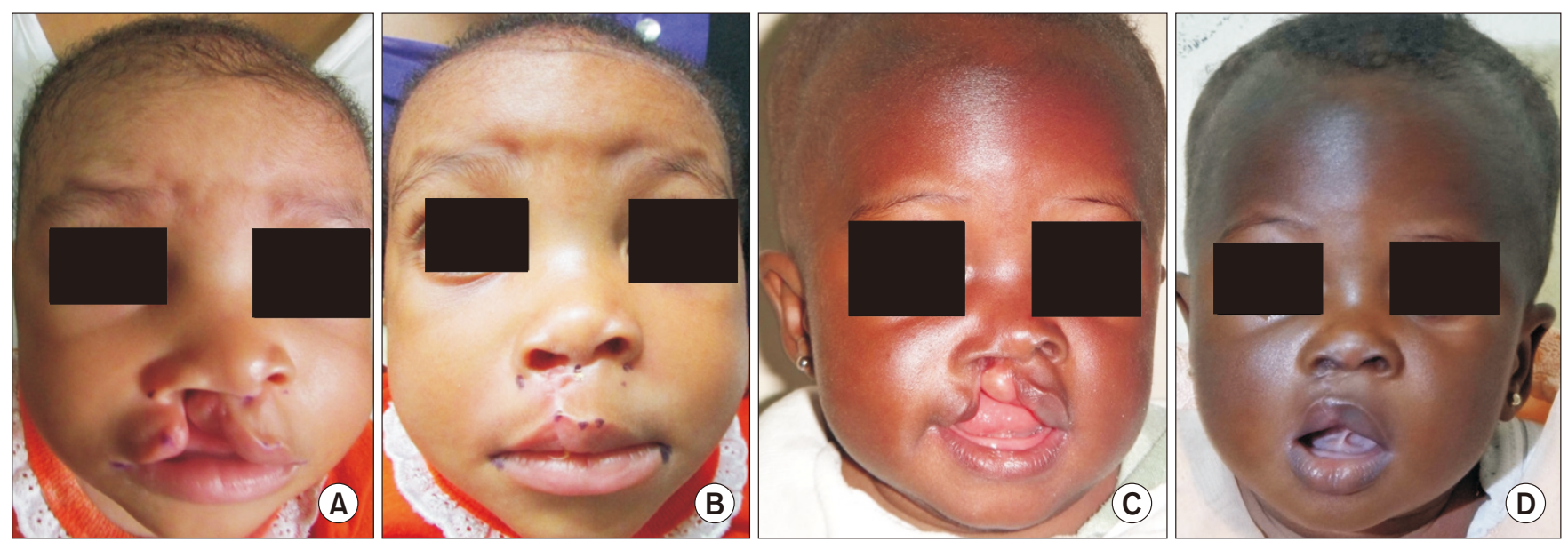

Fig. 1. A 4-month-old female with right unilateral cleft lip and alveolus, preoperative picture $(A)$ and postoperative picture (B) showing a repair with the Millard technique that the guardian judged to be satisfactory. A 4-month-old female with right unilateral cleft lip alveolus and palate, preoperative picture (C) and postoperative picture (D) showing a repair with the Tennison-Randall technique that the guardian judged to be satisfactory.

Adekunle Moses Adetayo et al: Unilateral cleft lip: evaluation and comparison of treatment outcome with two surgical techniques based on qualitative (subject/guardian and professional) assessment. J Korean Assoc Oral Maxillofac Surg 2019 

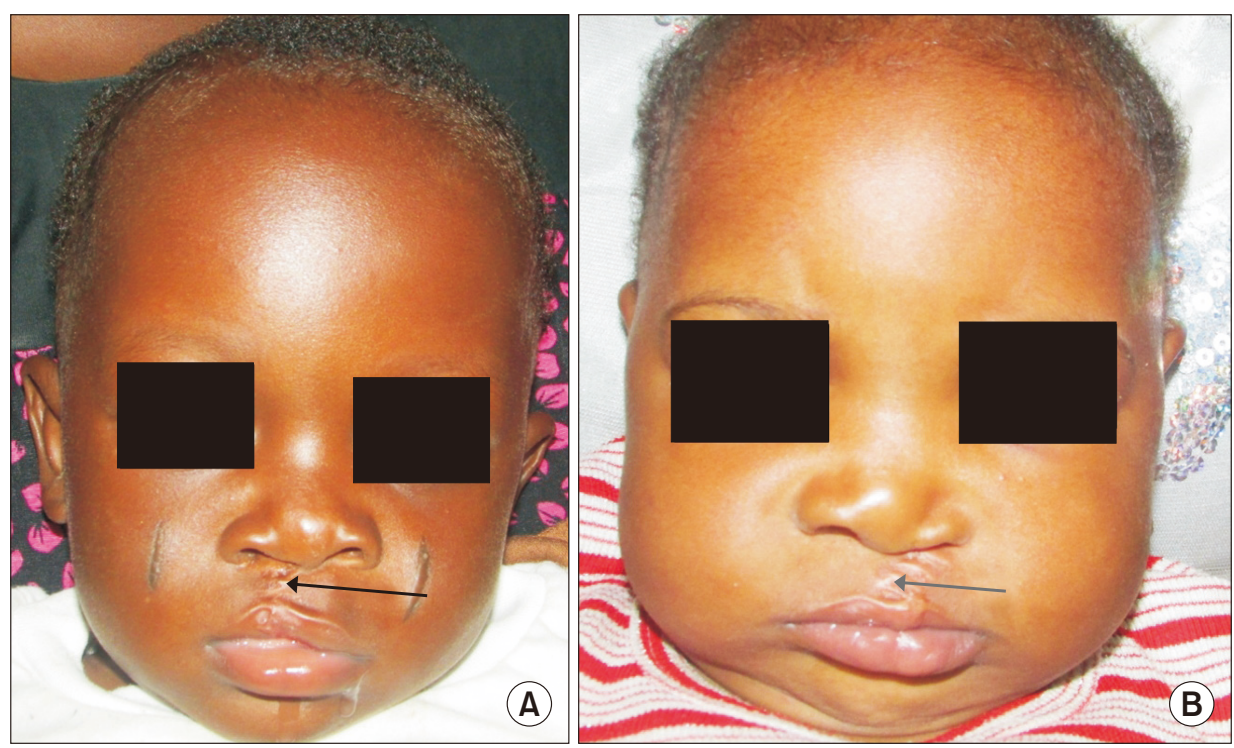

Fig. 2. A. Postoperative clinical picture of a 6-month-old male following Millard repair showing scar transgression of the philtral ridge (arrow). B. Postoperative clinical picture of a 6-month-old female following Tennison-Randall repair showing scar transgression of the philtral ridge (arrow).

Adekunle Moses Adetayo et al: Unilateral cleft lip: evaluation and comparison of treatment outcome with two surgical techniques based on qualitative (subject) guardian and professional) assessment. J Korean Assoc Oral Maxillofac Surg 2019
The outcome of nasal repair becomes worse as the width of the cleft deformity increases, but an experienced and skillful surgeon is able to achieve a good nasal appearance even in wide cleft deformities. However, various authors ${ }^{36,37}$ have proposed the use of a presurgical orthopedic technique for wide cleft deformity.

Columella deviation was higher in the Millard group than in TR group, but, unlike nasal symmetry, this was not significant. This, however, is in agreement with an earlier study by Abdurrazaq et al. ${ }^{32}$; these authors also reported poor nasal symmetry in the Millard group. Although primary rhinoplasty was not done after Millard repair ${ }^{1}$ in this study, the problem of an asymmetric nose even after primary nasal repair is well documented $^{8,38}$.

With regard to the assessor evaluations, only scar transgression of the philtral ridge was judged to differ between the two techniques. This coincided with 'the part of the scar that bothers me the most' in the guardian/patient evaluation. This is in agreement with prior studies ${ }^{7,23,34,35}$ that also reported a high percentage of scar transgression of the anatomical boundary with TR repair. In contrast, Holtmann and Wray ${ }^{27}$ and Chowdri et al. ${ }^{28}$, while working on 35 and 108 randomly selected patients, respectively, concluded that there was no significant difference between the two techniques in terms of transgression of the residual scar. Both techniques have been reported to produce a scar that transgresses a known anatomical boundary. Millard's technique transgresses the philtrum at the upper part due to the rotation incision, while TR transgresses it at the lower part due to the triangular flap that inserts in the medial element ${ }^{22}$.
There was a higher incidence of peaking and notching in the Millard group than the TR group, but this was not significant. High incidence of peaking, and notching in particular, has been noted in Millard repair by various studies ${ }^{7,23,34,39}$. The most obvious reason for this notching is straight line closure of the vermilion. However, unequal width of the lateral and medial cleft segments might also play a role depending upon the disparity in thickness on both sides of the cleft ${ }^{40}$. Bilwatsch et al. ${ }^{22}$ and Cheema et al. ${ }^{39}$ reported inadequate rotation of the medial element and turning in of the sutured edges as other causes of notching. Another factor may be an incision in the lateral lip segment that is made too far medially, thus going beyond the maximum vermilion thickness where all three segments (vermilion, skin, and muscle) are underdeveloped. Measures to prevent lip notching suggested in the literature include the use of the Noordhoff triangular flap to compensate for deficiency of the vermillion on the non-cleft side, adequate rotation of the medial element with a back cut that does not violate the vermilion, and adequate undermining of the skin and mucosa limited to a few millimeters from the edges ${ }^{40}$.

Nasal symmetry, columella centrality, and ala symmetry were all rated higher in the TR group than the Millard group, but without statistical significance. This is similar to what was reported by Holtmann and $\mathrm{Wray}^{27}$, Chowdri et al. ${ }^{28}$, and Fudalej et al. ${ }^{35}$, in other words no difference between these two techniques in nose appearance assessments.

Hypertrophic scars, of which more occurred in the Millard group than in the TR group, have also been reported in prior studies ${ }^{7,27,28,34,35}$. Hypertrophic scar is defined as the ac- 
cumulation of excessive collagen leading to raised scar that does not exceed the boundaries of the wound ${ }^{41}$. Although no definite relationship between the type of suture material used and formation of a hypertrophic scar has been established in the literature, some suture types such as silk and catgut have been reported to elicit a strong inflammatory reaction when used on the $\operatorname{skin}^{2}$. This might result in excessive formation of fibrous tissue, probably leading to hypertrophic scar formation $^{42}$. However, we used nylon sutures for repair in this study, which have been noted to elicit very little or no inflammatory reaction ${ }^{2}$. There is speculation that hypertrophic scarring might be technique biased ${ }^{42}$. However, verification of this will require a highly controlled study.

Essentially, we found no major differences in the overall results between Millard rotation-advancement repair and Tennison-Randall repair. Tennison-Randall lip repair is one of the most widespread primary reconstruction methods. The most important contributions of this technique to cleft surgery are recognition and preservation of Cupid's bow by lowering the peak in the margin of the cleft ${ }^{22}$. In contrast, the Millard rotation-advancement technique ${ }^{17}$, introduced in 1957 , has been reported to be the most widely used procedure for cleft lip repair because it places most of the scar along the natural philtral border and is more flexible than geometric closure techniques. Moreover, the Millard technique allows for complete muscular repair and minimizes the discarding of normal tissue.

Most cleft lip repairs were judged to be satisfactory by the guardians/subjects regardless of repair technique used. The main differences in outcomes between the two techniques were the location of the scar that the subject or guardian felt was the most bothersome, and the presence of nasal flattening at the cleft side. The upper part of the scar close to the nose was considered abnormal after Millard repair, while the lower part of the scar close to the lip was considered abnormal after Tennison-Randall repair. Coincidentally, assessors noted a difference in lip scar transgression of the philtral ridge between the two techniques. This suggests that both the Millard and Tennison-Randall techniques require significant improvements to improve the appearance of the scar on the upper and lower parts of the lip, respectively.

\section{Conclusion}

Expertise of the surgeon and/or individual preferences are important factors to consider when selecting a technique to repair a unilateral cleft lip, as we found no appreciable dif- ferences in outcomes between two widely used techniques in our study.

\section{ORCID}

Adekunle Moses Adetayo, https://orcid.org/0000-00027318-0810

Modupe Olushola Adetayo, https://orcid.org/0000-00016507-3436

Wasiu Lanre Adeyemo, https://orcid.org/0000-0002-02577853

Olutayo O. James, https://orcid.org/0000-0002-4788-5235

Michael O. Adeyemi, https://orcid.org/0000-0003-15133941

\section{Authors' Contributions}

A.M.A. was involved in the conception, planning, data collection, interpretation, analysis, and writing of the final manuscript. M.O.A. was involved in the statistical study planning, analysis, data interpretation, and writing of the final manuscript. W.L.A. was involved in study planning, data interpretation, and writing of the final manuscript. M.O.A. was involved in the data interpretation and writing of the final manuscript. O.O.J. was involved in the planning and writing of the final manuscript.

\section{Ethics Approval and Consent to Participate}

The study was approved by the Health Research and Ethics Committee of Lagos University Teaching Hospital (approval No. 34512).

\section{Consent for Publishing Photographs}

Written informed consent was obtained from the patients/ guardians for publication of this article and accompanying images.

\section{Conflict of Interest}

No potential conflict of interest relevant to this article was reported.

\section{References}

1. Arosarena OA. Cleft lip and palate. Otolaryngol Clin North Am 
2007;40:27-60, vi.

2. Koppel D. Cleft lip and palate: developmental abnormalities of the face, mouth and jaws. In: Russell RCG, Williams NS, Bulstrode CJK, eds. Bailey \& Love's short practice of surgery. 24th ed. London: Arnold; 2004:645-63.

3. Demke JC, Tatum SA. Analysis and evolution of rotation principles in unilateral cleft lip repair. J Plast Reconstr Aesthet Surg 2011;64:313-8.

4. Nwoku AL. Experiences on the surgical repair of unoperated adult cleft patients in Nigeria. Niger Med J 1976;4:417-21.

5. Tan O, Atik B. Triangular with Ala nasi (TAN) repair of unilateral cleft lips: a personal technique and early outcomes. J Craniofac Surg 2007; 18:186-97.

6. van de Ven B, Defrancq J, Defrancq E. Cleft lip surgery: a practical guide. Zgierz: Drukarnia WIST; 2008:1-27.

7. Christofides E, Potgieter A, Chait L. A long term subjective and objective assessment of the scar in unilateral cleft lip repairs using the Millard technique without revisional surgery. J Plast Reconstr Aesthet Surg 2006;59:380-6.

8. Nollet PJ, Kuijpers-Jagtman AM, Chatzigianni A, Semb G, Shaw WC, Bronkhorst EM, et al. Nasolabial appearance in unilateral cleft lip, alveolus and palate: a comparison with Eurocleft. J Craniomaxillofac Surg 2007;35:278-86.

9. Asher-McDade C, Roberts C, Shaw WC, Gallager C. Development of a method for rating nasolabial appearance in patients with clefts of the lip and palate. Cleft Palate Craniofac J 1991;28:385-90; discussion 390-1.

10. Roberts CT, Semb G, Shaw WC. Strategies for the advancement of surgical methods in cleft lip and palate. Cleft Palate Craniofac J 1991;28:141-9.

11. Rullo R, Carinci F, Mazzarella N, Festa VM, Farina A, Morano D, et al. Delaire's cheilorhinoplasty: unilateral cleft aesthetic outcome scored according to the EUROCLEFT guidelines. Int J Pediatr Otorhinolaryngol 2006;70:463-8.

12. Farkas LG, Hajnis K, Posnick JC. Anthropometric and anthroposcopic findings of the nasal and facial region in cleft patients before and after primary lip and palate repair. Cleft Palate Craniofac J 1993;30:1-12.

13. Johnson N, Sandy J. An aesthetic index for evaluation of cleft repair. Eur J Orthod 2003;25:243-9.

14. Kernahan DA, Stark RB. A new classification for cleft lip and cleft palate. Plast Reconstr Surg Transplant Bull 1958;22:435-41.

15. Kernahan DA. The striped Y--a symbolic classification for cleft lip and palate. Plast Reconstr Surg 1971;47:469-70.

16. Randall P. A triangular flap operation for the primary repair of unilateral clefts of the lip. Plast Reconstr Surg Transplant Bull 1959;23:331-47.

17. Millard DR. A primary camouflage of the unilateral harelook. In: Shoog T, Ivy RH, eds. Transactions of the International Society of Plastic Surgeons. Baltimore: Williams \& Wilkins; 1957:160-6.

18. Evans CA. Index may show outcome differences in unilateral cleft lip and palate patients at 5-years of age. Evid Based Dent 1999;1:7.

19. Gundlach KK, Schmitz R, Maerker R, Bull HG. Late results following different methods of cleft lip repair. Cleft Palate $\mathrm{J}$ 1982;19:167-71.

20. de Silva Amaratunga NA. Combining Millard's and Cronin's methods of unilateral cleft lip repair - a comparative study. Asian J Oral Maxillofac Surg 2004;16:5-9.

21. Dyalram-Silverberg D, Jamali M, Hoffman D, Lazow SK, Berger JR. Poster 23: comparison of the rotational advancement flap and an anatomical subunit approximation technique for closure of unilateral cleft lip. J Oral Maxillofac Surg 2009;67(Suppl):80-1.

22. Bilwatsch S, Kramer M, Haeusler G, Schuster M, Wurm J, Vairaktaris E, et al. Nasolabial symmetry following Tennison-Randall lip repair: a three-dimensional approach in 10-year-old patients with unilateral clefts of lip, alveolus and palate. J Craniomaxillofac Surg 2006;34:253-62.

23. Sameh E, Amr S, Ashraf E. Evaluation of primary unilateral cleft lip repair: a proposed scoring system. Egypt J Surg 2009;28:4-7.

24. Meyer E, Seyfer A. Cleft lip repair: technical refinements for the wide cleft. Craniomaxillofac Trauma Reconstr 2010;3:81-6.

25. Reddy SG, Reddy RR, Bronkhorst EM, Prasad R, Kuijpers Jagtman AM, Bergé S. Comparison of three incisions to repair complete unilateral cleft lip. Plast Reconstr Surg 2010;125:1208-16.

26. Zaleckas L, Linkevičienė L, Olekas J, Kutra N. The comparison of different surgical techniques used for repair of complete unilateral cleft lip. Medicina (Kaunas) 2011;47:85-90.

27. Holtmann B, Wray RC. A randomized comparison of triangular and rotation-advancement unilateral cleft lip repairs. Plast Reconstr Surg 1983;71:172-9.

28. Chowdri NA, Darzi MA, Ashraf MM. A comparative study of surgical results with rotation-advancement and triangular flap techniques in unilateral cleft lip. Br J Plast Surg 1990;43:551-6.

29. Tobiasen JM, Hiebert JM, Boraz RA. Development of scales of severity of facial cleft impairment. Cleft Palate Craniofac J 1991;28:419-24.

30. Tobiasen JM, Hiebert JM. Facial impairment scales for clefts. Plast Reconstr Surg 1994;93:31-41; discussion 42-3.

31. Al-Omari I, Millett DT, Ayoub AF. Methods of assessment of cleft-related facial deformity: a review. Cleft Palate Craniofac J 2005;42:145-56.

32. Abdurrazaq TO, Micheal AO, Lanre AW, Olugbenga OM, Akin LL. Surgical outcome and complications following cleft lip and palate repair in a teaching hospital in Nigeria. Afr J Paediatr Surg 2013;10:345-57.

33. Thomas PT, Turner SR, Rumsey N, Dowell T, Sandy JR. Satisfaction with facial appearance among subjects affected by a cleft. Cleft Palate Craniofac J 1997;34:226-31.

34. Chait L, Kadwa A, Potgieter A, Christofides E. The ultimate straight line repair for unilateral cleft lips. J Plast Reconstr Aesthet Surg 2009;62:50-5.

35. Fudalej P, Katsaros C, Bongaarts C, Dudkiewicz Z, Kuijpers-Jagtman AM. Nasolabial esthetics in children with complete unilateral cleft lip and palate after 1- versus 3-stage treatment protocols. J Oral Maxillofac Surg 2009;67:1661-6.

36. Millard DR. Extensions of the rotation-advancement principle for wide unilateral cleft lips. Plast Reconstr Surg 1968;42:535-44.

37. Mulliken JB, Martínez-Pérez D. The principle of rotation advancement for repair of unilateral complete cleft lip and nasal deformity: technical variations and analysis of results. Plast Reconstr Surg 1999;104:1247-60.

38. Horswell BB, Castiglione CL, Poole AE, Assael LA. The doublereversing Z-plasty in primary palatoplasty: operative experience and early results. J Oral Maxillofac Surg 1993;51:145-9; discussion 149-50.

39. Cheema SA, Asim M, Ahmad A. Comparison of outcomes between linear versus triangular flap repair techniques at vermilion in unilateral cleft lip repair. J Ayub Med Coll Abbottabad 2012;24:75-7.

40. Adenwalla HS, Narayanan PV. Primary unilateral cleft lip repair. Indian J Plast Surg 2009;42 Suppl:S62-70.

41. Kumar V, Abbas AK, Fausto N. Robbins and Cotran pathologic basis of disease. 7th ed. Philadelphia: Elsevier Saunders; 2005:113-7.

42. Edward E. Management of patients with orofacial clefts. In: Peterson LJ, Ellis E, Hupp JR, Tucker MR, eds. Contemporary oral and maxillofacial surgery. 4th ed. Estados Unidos: Mobsy; 2003:633.

How to cite this article: Adetayo AM, Adetayo MO, Adeyemo WL, James OO, MO Adeyemi. Unilateral cleft lip: evaluation and comparison of treatment outcome with two surgical techniques based on qualitative (subject/guardian and professional) assessment. J Korean Assoc Oral Maxillofac Surg 2019;45:141-51. https://doi.org/10.5125/jkaoms.2019.45.3.141 


\section{Appendix 1.}

\section{SUBJECT/GUARDIAN QUESTIONNAIRE}

Please answer the following questions and tick the appropriate boxes below. The aim is to identify your satisfaction with your cleft lip repair. In particular, we want to assess your impressions of the scar and wish to ascertain what bothers you most.

\begin{tabular}{|l|l|}
\hline 1 & Very satisfied (very happy) \\
\hline 2 & Doesn't bother me much (happy) \\
\hline 3 & Could have been better (okay) \\
\hline 4 & Not satisfied at all (unhappy) \\
\hline
\end{tabular}

1. Are you satisfied with the color of the scar?

\begin{tabular}{|l|l|l|l|l|l|l|l|}
\hline 1 & & 2 & & 3 & & 4 & \\
\hline
\end{tabular}

2. Are you satisfied with the texture (smoothness) of the scar?

\begin{tabular}{|l|l|l|l|l|l|l|l|}
\hline 1 & & 2 & & 3 & & 4 & \\
\hline
\end{tabular}

3. Are you satisfied with the thickness (amount of bulging above the skin) of the scar?

\begin{tabular}{|l|l|l|l|l|l|l|l|}
\hline 1 & & 2 & & 3 & & 4 & \\
\hline
\end{tabular}

4. Are you satisfied with the shape (lines, angles, etc.) of the scar?

\begin{tabular}{|l|l|l|l|l|l|l|l|}
\hline 1 & & 2 & & 3 & & 4 & \\
\hline
\end{tabular}

5. Are you satisfied with the width of the scar?

\begin{tabular}{|l|l|l|l|l|l|l|l|}
\hline 1 & & 2 & & 3 & & 4 & \\
\hline
\end{tabular}

6. Are you satisfied with the Cupid's bow?

\begin{tabular}{|l|l|l|l|l|l|l|l|}
\hline 1 & & 2 & & 3 & & 4 & \\
\hline
\end{tabular}

7. What part of the scar bothers you the most?

\begin{tabular}{|l|l|}
\hline Upper part close to nose & \\
\hline Middle part & \\
\hline Lower part close to lip & \\
\hline
\end{tabular}

8. Presence or absence of flattening of nostril at the cleft side?

\begin{tabular}{|l|l|}
\hline Yes & \\
\hline No & \\
\hline
\end{tabular}

9. Deviation of the columella?

\begin{tabular}{|l|l|}
\hline Yes & \\
\hline No & \\
\hline
\end{tabular}




\section{Appendix 2.}

\section{ASSESSOR EVALUATION FORM}

Thickness of scar

\begin{tabular}{|l|l|}
\hline Level with the surrounding skin & \\
\hline Depressed & \\
\hline Elevated & \\
\hline
\end{tabular}

Thickness of scar at the nostril sill

\begin{tabular}{|l|l|}
\hline Level with the surrounding skin & \\
\hline Depressed & \\
\hline Elevated & \\
\hline
\end{tabular}

Scar transgression of anatomical boundary (philtral ridge)

\begin{tabular}{|l|l|}
\hline Yes & \\
\hline No & \\
\hline
\end{tabular}

\section{Peaking}

\begin{tabular}{|l|l|}
\hline Yes & \\
\hline No & \\
\hline
\end{tabular}

Notching

\begin{tabular}{|l|l|}
\hline Yes & \\
\hline No & \\
\hline
\end{tabular}

Nostrils symmetrical

\begin{tabular}{|l|l|}
\hline Yes & \\
\hline No & \\
\hline
\end{tabular}

\section{Centrality of columella}

\begin{tabular}{|l|l|}
\hline Central & \\
\hline Deviated & \\
\hline
\end{tabular}

Alae on the cleft side

\begin{tabular}{|l|l|}
\hline Normal & \\
\hline Flattened & \\
\hline
\end{tabular}

Keloid/hypertrophic scar

\begin{tabular}{|l|l|}
\hline Yes & \\
\hline No & \\
\hline
\end{tabular}

